\title{
Optimasi Formula Tablet Piroksikam Menggunakan Eksipien Laktosa, Avicel pH-101, dan Amprotab dengan Metode Simplex Lattice Design
}

\section{Optimization of Formula of Piroxicam Tablets Using Excipients Lactose, Avicel pH 101, and Amprotab with Simplex Lattice Design Method}

\author{
Ikhwan Yuda Kusuma*, Rani Prabandari \\ Program Studi Farmasi,Universitas Harapan Bangsa, Jl. RadenPatah No.100, Banyumas, Indonesia \\ *E-mail: ikhwanyudakusuma@gmail.com
}

Received: 6 November 2019; Accepted: 27 Juni 2020; Published: 30 Juni 2020

\begin{abstract}
Abstrak
Piroksikam merupakan salah satu obat golongan NSAID dengan dosis kecil (10-20 mg/hari). Kelarutan piroksikam dalam air yang sangat kecil menimbulkan masalah pada proses absorbsi sehingga diperlukan formula yang optimum untuk membentuk tablet piroksikam yang memenuhi syarat sifat fisik tablet. Tujuan penelitian ini untuk membuat formula optimum dengan kombinasi eksipien laktosa, avicel pH-101, dan amprotab untuk memperoleh tablet piroksikam dengan sifat fisik dan disolusi yang baik. Tablet piroksikam dibuat 7 formula dengan kombinasi laktosa, avicel PH-101, dan amprotab sebanyak 2 batch . Metode pembuatan tablet piroksikam dengan cara cetak langsung. Pengujian sifat fisik tablet meliputi keseragaman bobot, keseragaman ukuran, kekerasan, kerapuhan, waktu hancur, serta uji disolusi, dan penetapan kadar. Berdasarkan metode simplex lattice design, laktosa merupakan faktor yang paling dominan dalam meningkatkan keseragaman kadar tablet. Interaksi kedua komponen avicel PH-101 dan amprotab merupakan faktor yang paling dominan dalam menurunkan kerapuhan tablet. Interaksi ketiga komponen laktosa, avicel PH-101, dan amprotab merupakan faktor yang paling dominan dalam menurunkan CV keseragaman bobot, meningkatkan keseragaman bobot, meningkatkan kekerasan, menurunkan waktu hancur, dan meningkatkan disolusi tablet. Pemilihan formula optimum ditentukan dengan metode simplex lattice design melalui diagram contour plot dan superimposed contour plot sehingga diperoleh area optimum dengan proporsi masing-masing bahan adalah sebagai berikut: laktosa (85,154-100\%), avicel PH-101 (0$12,437 \%)$, dan amprotab (0-5,425\%).
\end{abstract}

Kata Kunci: optimasi formula, piroksikam, simplex lattice design, tablet

\begin{abstract}
Piroxicam solubility in water is very small this cause problem in the process of absorption so that it's required an optimal formula to establish the physical properties of tablet quality for piroxicam tablets. The purpose of this research was creating formulas with the optimal combination of excipients lactose, Avicel pH 101, and piroxicam amprotab to obtain tablets with good physical properties and disolution. Seven piroxicam tablet formulas were made with a combination of lactose, avicel PH-101, and Amprotab on 2 batches. Method for making tablets piroxicam was established by direct compression. Tests included were the physical properties of piroxicam tablets tablets weight uniformity, uniformity of size, hardness, brittleness, disintegration test, as well as dissolution test, and content uniformity. Based on the simplex lattice design method, lactose is a dominant factor to improved the uniformity of tablet's concentartions. Interaction of two components avicel $\mathrm{PH}-101$ and amprotab is a dominant factor to reduced vulnerability. Interaction of three components lactose, avicel PH-101 and amprotab is a dominant factor to lowered the value coefisien variation of weight uniformity, increased hardness, decreased the disintegration, and improved dissolution of tablets. Selection of the optimum formula was determined by the method of simplex lattice design through diagrams superimposed contour plots and contour plots for obtaining the optimal proportions of each ingredient as follows: lactose (85,154-100\%), avicel PH-101 (0-12,437\%), and amprotab $(0-5,425 \%)$.
\end{abstract}

Keywords: optimization, piroxicam, simplex lattice design, tablet 


\section{PENDAHULUAN}

Perkembangan teknologi informasi saat ini sudah sangat pesat. Berbagai disiplin ilmu sudah tidak bisa dipisahkan dengan teknologi. Karena banyak pekerjaan yang dipermudah dengan adanya teknologi. Salah satunya dalam bidang kefarmasian. Berkembangnya ilmu pengetahuan dan teknologi di bidang farmasi mendorong farmasis membuat suatu formulasi yang tepat dengan membuat suatu strategi dan desain bentuk sediaan yang acceptable sesuai dengan efek yang diharapkan dan reproducible dari batch ke batch (Junaedi dan Diana, 2018).

Teknologi farmasi mencakup semua aspek yang terkait dengan pabrikasi sediaan obat baik bahan aktif obat maupun exipient (bahan tambahan). Kemajuan teknologi tablet, termasuk peralatan produksi kontinu, teknologi proses analitis (PAT) dan perangkat lunak yang diperlukan untuk produksi skala komersial, membantu meningkatkan reproduktifitas, akurasi, dan konsistensi. Aspek-aspek ini berdampak pada produksi kualitas, keamanan, dan kemanjuran tablet yang diformulasikan. Untuk itu kualitas sediaan obat tidak hanya berfokus pada bahan aktif saja, tetapi berkaitan pula dengan pemilihan bahan tambahan yang tepat. Pengembangan eksipien perlu dilakukan baik di tingkat penelitian maupun realisasi pabrikasi di industri yang bertujuan untuk memperbaiki sifat fisika kimia sediaan obat, sehingga diperoleh formula yang optimum dalam ketersediaan farmasetik, ketersediaan hayati dan efek yang dihasilkan (Challener, 2015).

Suatu bahan aktif harus melalui tahapan preformulasi dan formulasi. Salah satunya adalah tahap formulasi yang memerlukan desain dan strategi yang dilakukan melalui optimasi yang terkonsep baik menggunakan metode factorial design (FD), maupun simplex lattice design (SLD) agar dappat menghasilkan produk yang berkualitas.

Tablet merupakan sediaan obat padat takaran tunggal yang dicetak dari sebuk kering, kristal atau granulat, umumnya dengan penambahan eksipien pada mesin yang sesuai dengan menggunakan suatu tekanan tinggi. Banyak masalah yang muncul dalam formulasi dan pembuatannya, seperti kecepatan alir bahan, daya kompresibilitas, disolusi yang kurang baik, profil disolusi dan masalah inkompatibilitas antara komponenkomponen penyusun sediaan obat (Murtini dan Yetri, 2018). Obat dalam bentuk sediaan padat berupa tablet salah satunya adalah Piroksikam.

Piroksikam merupakan obat golongan anti inflamasi non steroid yang umum digunakan untuk pengobatan rheumatoid arthitis dan osteoarthritis (Dipiro et al., 2016). Piroksikam mempunyai waktu paruh eliminasi yang panjang, sehingga diberikan dengan dosis sekali sehari untuk membantu kepatuhan penderita (Katzung, 2019). Piroksikam termasuk Biopharmaceutic Classification System Class 2 yang memiliki karakteristik kelarutan dalam air rendah, permeabilitas dalam usus tinggi sehingga proses absorbsi cepat tetapi profil disolusinya buruk (Islami et al., 2020).

Piroksikam termasuk obat dosis rendah dengan dosis lazim 10-20 mg per hari sehingga pemilihan eksipien dan optimasi formula sangat mempengaruhi sifat fisik tablet. Eksipien yang dipilih meliputi laktosa, avicel PH-101, dan amprotab. Laktosa sebagai pengisi untuk memenuhi bobot tablet yang diinginkan. Laktosa ini mempunyai sifat alir dan kompaktibilitas yang baik sehingga dapat memperbaiki sifat alir massa serbuk yang dihasilkan. Avicel PH-101 (mycrocristaline cellulose) berfungsi sebagai bahan pengikat dengan potensi daya ikat yang kuat, dan amprotab (amilum manihot) sebagai penghancur yang merupakan koloida hidrofilik yang mempunyai kapasitas absorbsi yang besar sehingga dalam tablet bahan ini akan mengembang, menjadikan tablet pecah dan hancur.

Pada penelitian sebelumnya, dinyatakan bahwa avicel pH 101 memberikan efek positif untuk meningkatkan kekerasan dan kerapuhan pada tablet. Hal ini merupakan 
ukuran homogenitas yang baik antara kadar zat aktif maupun eksipien (Zen et al., 2015), sehingga alasan penggunaan avicel pada penelitian ini sangat mendukung untuk digunakan sebagai bahan pengikat dengan potensi daya ikat yang kuat.

Laktosa memiliki sifat hidrofilik sebagai ekspien yang mempunyai pengaruh yang lebih besar terhadap kompaktibilitas dan flowabilitas. Pada penggunaan laktosa sebagai eksipien tablet, adanya peningkatan konsentrasi laktosa akan menyebabkan peningkatan kekerasan tablet. Sehingga apabila dikombinasikan dengan avicel maka akan memperbaiki sifat alir massa serbuk yang dihasilkan oleh avicel tersebut. Hal inilah yang menjadi dasar penggunaan laktosa sebagai bahan pengisi untuk memenuhi bobot tablet yang diinginkan (Gajera et al., 2016). Sedangkan menurut Ermawati et al (2018), amprotab merupakan nama dagang dari amilum manihot, merupakan salah satu bahan penghancur. Amprotab dapat mempengaruhi sifat fisik tablet terutama waktu hancur karena amprotab memiliki kekuatan pada aksi kapiler yang akan menarik cairan ke dalam tablet, sehingga dalam formulasi tablet bahan ini akan mengembang dan menjadikan tablet pecah dan hancur kemudian melarut.

Penelitian ini bertujuan untuk mendapatkan formula yang paling optimal dengan eksipien laktosa, avicel PH-101 dan amprotab dengan metode simplex lattice design 3 faktorial, sehingga diperoleh proporsi masing-masing eksipien yang diharapkan menghasilkan formula dengan profil disolusi dan sifat fisik yang optimum.

\section{METODE PENELITIAN}

\section{Alat}

Alat-alat yang digunakan yaitu seperangkat alat gelas, timbangan digital, mesin cetak tablet single punch, cube mixer, alat uji kekerasan (hardness tester), alat uji kerapuhan (friabilitor), jangka sorong, ayakan mesh 40, stopwatch, dissolution tester, dan spektrofotometer UV-Vis (Shimadzu UVmini-1240).

\section{Bahan}

Bahan-bahan yang digunakan yaitu piroksikam, laktosa, avicel PH-101, amprotab, magnesium stearate, metanol, $\mathrm{HCl}, \mathrm{NaCl}$, dan aquadest.

\section{Formulasi}

Penentuan formula dengan model simplex lattice design dilakukan menggunakan variasi eksipien yaitu laktosa (komponen A), avicel pH-101 (komponen B), dan amprotab (komponen C) dalam proporsi tertentu. Formula umum tiap tablet (berat total $=150$ mg) dapat dilihat pada tabel 1.

Pencampuran dilakukan dengan cara masing-masing komponen bahan diayak dengan ayakan mesh 40, ditimbang sesuai dengan formula desain dan dicampur menggunakan cube mixer. Piroksikam

Tabel 1. Formula tablet piroksikam secara simplex lattice design dengan bobot tablet $150 \mathrm{mg}$

\begin{tabular}{lcccccc}
\hline \multirow{2}{*}{ Formula } & \multicolumn{5}{c}{ Bahan $(\mathbf{m g})$} & Bobot \\
\cline { 2 - 5 } & piroksikam & $\begin{array}{c}\text { Mg } \\
\text { stearat }\end{array}$ & laktosa & $\begin{array}{c}\text { avicel } \\
\text { PH } \\
\text { Tablet }\end{array}$ & amprotab & \\
\hline F I & 10 & 5 & 135 & 0 & 0 & $150 \mathrm{mg}$ \\
F II & 10 & 5 & 0 & 135 & 0 & $150 \mathrm{mg}$ \\
F III & 10 & 5 & 0 & 0 & 135 & $150 \mathrm{mg}$ \\
F IV & 10 & 5 & 67,5 & 67,5 & 0 & $150 \mathrm{mg}$ \\
F V & 10 & 5 & 67,5 & 0 & 67,5 & $150 \mathrm{mg}$ \\
F VI & 10 & 5 & 0 & 67,5 & 67,5 & $150 \mathrm{mg}$ \\
F VII & 10 & 5 & 45 & 45 & 45 & $150 \mathrm{mg}$ \\
\hline
\end{tabular}

Keterangan : tiap formula dibuat tablet dalam 2 batch $(1$ batch $=200$ tablet $)$ 
dicampur dengan eksipien laktosa, avicel $\mathrm{pH}-$ 101 dan amprotab sesuai dengan komposisi bahan pada formula desain hingga homogen dalam cube mixer selama 10 menit dengan kecepatan putar $30 \mathrm{rpm}$. Campuran kemudian ditambahkan Mg stearat dan dicampur selama 2 menit (30 rpm).

Formula tablet piroksikam dimasukkan ke dalam ruang cetakan dan dikempa oleh kedua gerakan punch atas dan bawah. Massa tablet dicetak dengan kecepatan putaran mesin 20 rpm. Parameter kekerasan tablet dikendalikan berada pada kisaran 4-10 kg. Berat total masing-masing tablet dibuat konstan sekitar $150 \mathrm{mg}$.

\section{Uji Sifat Fisik Tablet Piroksikam}

Keseragaman Ukuran

Sejumlah 20 tablet dari masing-masing batch diambil dan diukur diameter tablet dan ketebalan tablet menggunakan jangka sorong. Kecuali dinyatakan lain, diameter tablet tidak lebih dari tiga kali dan tidak kurang dari 11/3 (satu sepertiga) kali tebal tablet (USP, 2018).

\section{Keseragaman Bobot}

Sejumlah 20 tablet yang telah dibersihkan dari debu ditimbang satu per satu, dihitung bobot rata-rata tiap tablet. Jika dihitung satu per satu, tidak boleh lebih dari 2 tablet yang masing-masing bobotnya menyimpang dari bobot rata-ratanya lebih besar dari harga yang ditetapkan pada kolom A. Selain itu, tidak satu tablet pun yang bobotnya menyimpang dari bobot rata-ratanya lebih dari harga yang ditetapkan kolom B (USP, 2018).

\section{Kekerasan Tablet}

Sebuah tablet diletakkan di tengah dan tegak lurus pada hardness tester, mula-mula pada posisi nol. Alat diputar pelan-pelan hingga tablet pecah. Skala yang dicapai pada tablet saat pecah atau hancur dibaca (USP, 2018)

\section{Kerapuhan Tablet}

Sejumlah 20 tablet dibebasdebukan dan ditimbang dalam neraca analitik yang dinyatakan sebagai M1. Kemudian tablet dimasukkan ke dalam friabilator. Alat dijalankan selama 4 menit dengan kecepatan 25 putaran per menit. Setelah 4 menit atau 100 kali putaran, tablet dikeluarkan dari alat, dibebasdebukan lagi dan ditimbang yang kemudian dinyatakan sebagai M2. Kerapuhan tablet yang merupakan selisih berat tablet sebelum dan sesudah diuji tidak boleh berkurang lebih $1 \%$ dari berat awal tablet awal uji.

\section{Waktu Hancur}

Waktu hancur tablet adalah waktu yang diperlukan untuk hancurnya tablet dalam waktu yang sesuai, sehingga tidak ada bagian yang tertinggal di atas kasa (USP, 2018). Waktu hancur untuk tablet tidak bersalut adalah kurang dari 15 menit. Peralatan uji waktu hancur terdiri dari rak keranjang yang mempunyai enam lubang yang terletak vertikal di atas ayakan mesh nomor 10. Selama percobaan tablet diletakkan pada tiap lubang keranjang. Keranjang tersebut bergerak naik turun pada larutan transparan dengan kecepatan 29-32 putaran permenit. Interval waktu hancur adalah 5-30 menit (USP, 2018). Disintegrasi terjadi sempurna jika sudah tidak ada partikel tablet (kecuali penyalut) yang masih tertinggal di atas ayakan (USP, 2018).

\section{Uji Disolusi}

Medium disolusi yang digunakan adalah $1,5 \%$ natrium lauril sulfat dalam cairan lambung tanpa pepsin sebanyak $900 \mathrm{~mL}$ yang dimasukkan ke dalam labu disolusi. Cara pembuatannya yaitu dengan menimbang 2,0 g $\mathrm{NaCl}$, dilarutkan dalam $200 \mathrm{~mL}$ aquades, dan ditambahkan $7 \mathrm{~mL} \quad \mathrm{HCl} 37 \%$. Larutan diencerkan dengan menambahkan aquades di dalam labu ukur hingga volume $1 \mathrm{~L}$. Menurut USP 41 larutan diatur pada $\mathrm{pH}$ 1,2 $\pm 0,05$ dan ditambahkan 5,0 g natrium lauril sulfat dalam larutan tersebut.

Uji disolusi pada penelitian ini dilakukan dengan menggunakan dissolution tester tipe basket. Kecepatan putar pengaduk basket diatur pada kecepatan $50 \mathrm{rpm}$ dengan jarak pengaduk basket dari dasar adalah $2,5 \mathrm{~cm}$. Menurut USP 41 suhu percobaan dipertahankan berada pada 37-38 ${ }^{\circ} \mathrm{C}$. Dilakukan 2 kali replikasi untuk uji disolusi tablet. 
Sampel hasil disolusi tablet piroksikam diambil dari medium disolusi pada menit ke 5, $10,20,45,60$, dan 90, masing-masing sebanyak 5,0 $\mathrm{mL}$. Sampel yang diambil kemudian diganti dengan medium disolusi baru dalam jumlah yang sama yaitu $5,0 \mathrm{~mL}$ sehingga volume medium disolusi tetap. Dilakukan 2 kali replikasi dalam uji ini (USP, 2018).

Sampel yang telah diperoleh dari menit ke 5, 10, 20, 45, 60, dan 90 diukur absorbansinya pada spektrofotometer UV pada panjang gelombang maksimum piroksikam dalam medium disolusi. Hasil absorbansi yang diperoleh dimasukkan dalam persamaan regresi linier untuk memperoleh konsentrasinya.

Penetapan panjang gelombang maksimum piroksikam

Piroksikam ditimbang seksama $50 \mathrm{mg}$ dan dilarutkan dalam $100 \mathrm{~mL}$ medium disolusi. Larutan tersebut kemudian diencerkan hingga diperoleh konsentrasi 10 $\mu \mathrm{g} / \mathrm{mL}$ dengan cara $1 \mathrm{~mL}$ larutan diencerkan dalam $50 \mathrm{~mL}$ medium disolusi. Larutan dengan konsentrasi $10 \mu \mathrm{g} / \mathrm{mL}$ dibaca absorbansinya pada panjang gelombang 180$380 \mathrm{~nm}$.

\section{Penentuan kurva baku piroksikam}

Larutan baku piroksikam 50 $\mathrm{g} / 100 \mathrm{~mL}$ diencerkan dalam medium disolusi, sehingga diperoleh 6 konsentrasi larutan baku yaitu $4 \mu \mathrm{g} / \mathrm{mL}, 5 \mu \mathrm{g} / \mathrm{mL}, 6 \mu \mathrm{g} / \mathrm{mL}, 7 \mu \mathrm{g} / \mathrm{mL}, 8 \mu \mathrm{g} / \mathrm{mL}$, dan $10 \mu \mathrm{g} / \mathrm{mL}$. Absorbansi larutan baku dibaca pada panjang gelombang maksimum. Dari hasil pembacaan panjang gelombang maksimum dibuat kurva hubungan absorbansi sebagai fungsi konsentrasi sehingga diperoleh persamaan regresi linier $\mathrm{y}=\mathrm{bx}+\mathrm{a}$.

Kadar piroksikam ditetapkan dari persamaan garis regresi linier hubungan antara absorbansi dengan kadar piroksikam dalam medium disolusi. Pengungkapan data disolusi pada penelitian ini dilihat melalui nilai konsentrasi pada $\mathrm{t}=45$ menit $\left(\mathrm{C}_{45}\right)$ mengacu pada syarat yang ditetapkan dalam USP 46 yang menyatakan bahwa kadar piroksikam pada tablet piroksikam pada $\mathrm{t}=45$ menit tidak kurang dari $75 \%$.

\section{Uji Keseragaman kadar tablet piroksikam}

Penetapan panjang gelombang maksimum dilakukan dengan menimbang seksama sebanyak $50 \mathrm{mg}$ piroksikam dan dilarutkan dalam $100 \mathrm{~mL}$ HCl-metanol (1:1200). Larutan tersebut kemudian diencerkan hingga diperoleh konsentrasi $10 \mu \mathrm{g} / \mathrm{mL}$ dengan cara $1 \mathrm{~mL}$ larutan diencerkan dalam $50 \mathrm{~mL}$ HCl-metanol (1:1200). Larutan dengan konsentrasi 10 $\mu \mathrm{g} / \mathrm{mL}$ dibaca absorbansinya pada panjang gelombng 180-380 nm. Secara teoritik piroksikam mempunyai panjang gelombang maksimum 333 nm (USP, 2018).

Keseragaman kadar dalam tablet piroksikam diuji dengan satu tablet piroksikam dilarutkan dalam $100 \mathrm{~mL} \mathrm{HCl}$ metanol (1:1200) sehingga diperoleh konsentrasi teoritik $10 \mathrm{mg}$ piroksikam/100 $\mathrm{mL}$. Diambil $1 \mathrm{~mL}$ larutan piroksikam $10 \mathrm{mg} / 100 \mathrm{~mL}$ kemudian diencerkan menggunakan HCl-metanol (1:1200) hingga $10 \mathrm{~mL}$, sehingga diperoleh larutan piroksikam dengan konsentrasi teoritik $10 \mu \mathrm{g} / \mathrm{mL}$. Larutan tersebut dibaca absorbansinya pada panjang gelombang maksimum sehingga diperoleh absorbansi sampel. Kadar piroksikam dalam tablet dihitung dengan mengkonversi absorbansi sampel menggunakan persamaan regresi linier kurva baku $\mathrm{y}=\mathrm{bx}+\mathrm{a}$.

Pengujian dilakukan terhadap 10 tablet dengan cara yang sama. Kemudian dihitung kadar rata-rata piroksikam tiap tablet. Menurut monografi kadar piroksikam tidak kurang dari $97 \%$ dan tidak lebih dari $103 \%$ (USP, 2018).

\section{Pemilihan formula optimum tablet piroksikam}

Pemilihan formula optimum tablet piroksikam ditentukan melalui pendekatan simplex lattice design berdasarkan persamaan berikut:

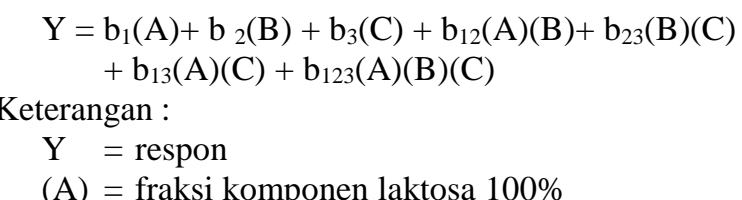


(B) = fraksi komponen avicel 100\%

(C) = fraksi komponen amprotab 100\%

$(\mathrm{A})(\mathrm{B})=$ fraksi komponen laktosa $50 \%$ dan avicel $50 \%$

$(\mathrm{A})(\mathrm{C})=$ fraksi komponen laktosa $50 \%$ dan amprotab 50\%

(B)(C) = fraksi komponen avicel $50 \%$ dan amprotab $50 \%$

$(\mathrm{A})(\mathrm{B})(\mathrm{C})=$ fraksi komponen laktosa $33,33 \%$, avicel 33,33\% dan amprotab 33,33\%

$b_{1}, b_{2}, b_{3}=$ koefisien regresi dari $(A),(B),(C)$

$\mathrm{b}_{12}, \mathrm{~b}_{13}, \mathrm{~b}_{23}=$ koefisien regresi dari $(\mathrm{A})-(\mathrm{B}),(\mathrm{A})$ (C), (B) - (C)

$\mathrm{b}_{123}=$ koefisien regresid $\operatorname{ari}(\mathrm{A})-(\mathrm{B})-(\mathrm{C})$

Data yang diperoleh dimasukkan dalam persamaan untuk memperoleh nilai koefisien, untuk menentukan koefisien (A), dilakukan percobaan dengan menggunakan satu bagian laktosa (100\% laktosa), untuk menentukan koefisien (B), diperlukan percobaan menggunakan $100 \%$ avicel, untuk menentukan koefisien (C), diperlukan percobaan menggunakan $100 \%$ amprotab, untuk menentukan koefisien (A)(B) diperlukan percobaan menggunakan campuran laktosa-avicel (50\%:50\%), untuk menentukan koefisien $(\mathrm{A})(\mathrm{C})$ diperlukan percobaan menggunakan campuran laktosaamprotab (50\% : 50\%), untuk menentukan koefisien (B)(C) diperlukan percobaan menggunakan campuran avicel-amprotab $(50 \%: 50 \%)$, dan untuk menentukan koefisien $(\mathrm{A})(\mathrm{B})(\mathrm{C})$ diperlukan percobaan menggunakan campuran laktosa-avicelamprotab (33,33\%:33,33\%:33,33\%). Selanjutnya diperoleh persamaan untuk menghitung respon sehingga profil sifat campuran secara teoritis dengan berbagai proporsi dapat ditentukan. Setelah semua nilai didapat dimasukkan ke software DesignExpert $囚$.

\section{HASIL DAN PEMBAHASAN}

Hasil uji keseragaman bobot untuk 7 formula diperoleh hasil yaitu bobot tablet piroksikam mendekati nilai $150 \mathrm{mg}$ dengan nilai $\mathrm{CV}<5 \%$ sesuai dengan persyaratan uji keseragaman bobot. Hasil uji keseragaman bobot menunjukkan tidak lebih dari 2 tablet yang bobotnya menyimpang dari bobot rataratanya lebih besar dari $10 \% \quad(135,225-$ $165,275 \mathrm{mg}$ ) dan tidak satupun tablet yang bobotnya menyimpang dari bobot rata-ratanya lebih dari $20 \%(120,2-180,3 \mathrm{mg})$, artinya berdasarkan Farmakope Indonesia semua formula tablet memenuhi syarat uji keseragaman bobot.

Menurut Wirastuty (2017) dan Rohmani dan Hilda (2019) menyatakan bahwa jika coefisien variation (CV) kurang dari 5\% artinya keseragaman bobot tablet tersebut dapat dikatakan baik. Semakin kecil nilai CV, maka variasi bobot akan semakin kecil dan dapat menghasilkan tablet yang seragam. Hasil perhitungan $\mathrm{CV}$ ketujuh formula menunjukkan besarnya kurang dari 5\%, sehingga dapat dikatakan bahwa semua formula memenuhi persyaratan. Keseragaman bobot dipengaruhi oleh sifat alir campuran pada proses pengisian ruang kompresi. Formula yang mempunyai sifat alir yang baik akan mempunyai kemampuan yang seragam dalam mengisi ruang kompresi sehingga variasi bobot tablet kecil (Hadisoewignyo and Fudholi, 2016). Persamaan untuk CV keseragaman bobot dapat diperoleh menerut pendekatan SLD yaitu :

$$
\begin{aligned}
& \mathrm{Y}=0,485(\mathrm{~A})+0,371(\mathrm{~B})+0,415(\mathrm{C})- \\
& 0,164(\mathrm{~A})(\mathrm{B})+0,792(\mathrm{~A})(\mathrm{C})+0,58(\mathrm{~B})(\mathrm{C})- \\
& 1,252(\mathrm{~A})(\mathrm{B})(\mathrm{C}) \ldots \ldots \ldots \ldots \ldots \ldots \ldots \ldots \ldots \ldots \ldots \ldots \ldots \ldots \ldots \ldots \ldots \ldots \ldots \ldots \ldots \ldots \ldots \ldots
\end{aligned}
$$

Berdasarkan Gambar 1, diagram contour plot keseragaman bobot menunjukkan area berwarna biru merupakan daerah yang memenuhi persyaratan uji keseragaman bobot dan dapat digunakan dalam optimasi formula tablet piroksikam. Hal ini menunjukkan bahwa semua area memenuhi syarat, dengan interaksi ketiga komponen laktosa, avicel PH101, dan amprotab yang paling dominan menurunkan nilai CV sehingga bobot tablet menjadi lebih seragam dan membantu dalam analisis kontrol kandungan obat secara sederhana dengan asumsi bahwa dengan keseragaman bobot tinggi maka keseragaman kandungan tinggi (Hadisoewignyo and Fudholi, 2016). 


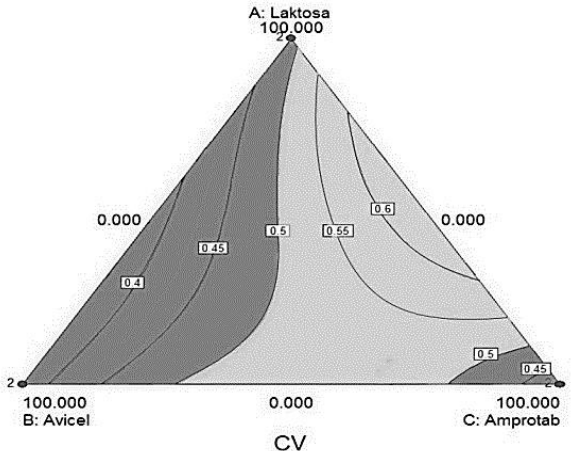

Gambar 1. Contour plot keseragaman bobot tablet piroksikam dengan kombinasi laktosa, avicel PH101, dan amprotab

Area optimum dipilih pada nilai $\mathrm{CV}$ 0$0,5 \%$, ditunjukkan oleh area berwarna biru tua, karena dengan nilai $\mathrm{CV}$ yang semakin kecil akan menghasilkan tablet yang bobotnya lebih seragam serta variasi bobot akan semakin kecil (Hadisoewignyo dan Fudholi, 2016).

Data yang diperoleh dari hasil analisis menunjukkan bahwa ketujuh formula memenuhi persyaratan uji sifat fisik keseragaman ukuran tebal dan diameter tablet piroksikam karena masih dalam rentang yang diijinkan yaitu diameter tidak boleh lebih dari tiga kali tebal tablet (tidak boleh lebih dari $0,798 \mathrm{~cm}$ ) dan tidak boleh kurang dari satu sepertiga tebal tablet (tidak boleh kurang dari $0,355 \mathrm{~cm})$. Hal tersebut dikarenakan pada pembuatan masing-masing formula tinggi rendahnya punch dan tekanan dari mesin yang konsisten. Selain itu, sifat alir dari formula juga mempengaruhi keseragaman pengisian ruang die. Formula yang memiliki sifat alir baik akan memiliki ukuran tablet yang lebih seragam (Tovey, 2018).

Pada beban kempa yang konstan, ketebalan tablet bervariasi dengan berubahnya pengisian die, dengan distribusi ukuran partikel serta kepadatan campuran partikel yang dikempa, dan dengan berat tablet, sementara pada keadaan pengisian die yang konstan, ketebalan bervariasi dengan berubahnya beban kompresi (Murtini dan Yetri, 2018).
Kekerasan tablet yang baik adalah $4 \mathrm{~kg}$ sampai $10 \mathrm{~kg}$ (Rori et al, 2016). Kekerasan dan kerapuhan tablet ini berbanding terbalik. Tablet yang memiliki kekerasan tinggi berarti ikatan antar partikel kuat, sehingga apabila terjadi goncangan tablet tidak mudah rusak. Hal ini berarti bahwa tablet dengan kekerasan yang tinggi memiliki kerapuhan yang rendah (Graham, 2019). Kekerasan yang tinggi juga merupakan salah satu indikator waktu hancur yang lebih lama sehingga berhubungan pula dengan disolusi tablet yang lebih rendah.

Analisis dari data yang diperoleh menunjukkan bahwa sebanyak 6 formula tablet (F I, F III, F IV, F V, F VI, F VII) memenuhi persyaratan kekerasan tablet yaitu kekerasannya berada dalam rentang 4-10 kg, namun pada F II (100\% avicel PH-101) memiliki kekerasan yang sangat tinggi yaitu $14,77 \mathrm{~kg}$ dan tidak memenuhi persyaratan uji kekerasan pada Farmakope Indonesia. Hal ini terjadi karena avicel $\mathrm{PH}-101$ memiliki daya ikat yang kuat dalam campuran untuk membentuk tablet yang keras, sehingga pada komposisi yang besar (lebih dari 70\%), tablet yang menggunakan bahan tambahan ini menjadi terlalu keras (Murtini dan Yetri, 2018).

Persamaan untuk kekerasan dapat diperoleh menurut pendekatan SLD yaitu :

$$
\begin{aligned}
& Y=4,670(\mathrm{~A})+14,775(\mathrm{~B})+3,730(\mathrm{C})- \\
& 2,710(\mathrm{~A})(\mathrm{B})+13,160(\mathrm{~A})(\mathrm{C})- \\
& 0,71(\mathrm{~B})(\mathrm{C})+19,661(\mathrm{~A})(\mathrm{B})(\mathrm{C})
\end{aligned}
$$

Menurut persyaratan tablet untuk kekerasan yang baik berada dalam rentang 4$10 \mathrm{~kg}$ (Rori et al., 2016). Berdasarkan Gambar 2 , diagram contour plot kekerasan tablet menunjukkan area berwarna hijau merupakan daerah yang memenuhi persyaratan uji kekerasan tablet dan dapat digunakan dalam optimasi formula tablet piroksikam. Area optimum dipilih pada nilai kekerasan 4-6 kg ditunjukkan oleh area berwarna hijau tua, karena kekerasan yang lebih rendah juga merupakan salah satu indikator waktu hancur yang lebih cepat sehingga berhubungan pula 
dengan disolusi tablet yang lebih tinggi (Graham, 2019).

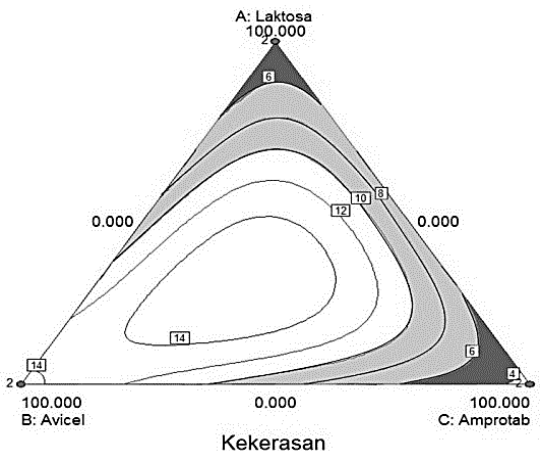

Gambar 2. Contour plot kekerasan tablet piroksikam dengan kombinasi laktosa, avicel PH-

101, dan amprotab berdasarkan metode SLD

Interaksi ketiga komponen laktosa, avicel PH-101, dan amprotab merupakan faktor yang paling dominan dalam meningkatkan kekerasan. Laktosa memiliki sifat kompaktibilitas yang tinggi, sehingga pada proses formulasi laktosa mampu menghasilkan tablet dengan kekerasan yang baik. Avicel PH-101 memiliki daya ikat yang kuat karena adanya ikatan hidrogen sehingga membentuk tablet yang keras. Amprotab memiliki kompaktibilitas yang rendah sehingga tablet lebih mudah rapuh. Amprotab merupakan bahan penghancur yang memiliki potensi daya ikat rendah sehingga tablet yang dihasilkan lebih rapuh dan terjadi capping sehingga dalam formulasi sering dikombinasikan dengan avicel $\mathrm{PH}-101$ untuk meningkatkan daya ikat campuran dalam formula tablet (Tovey, 2018). Kombinasi laktosa, avicel PH-101, dan amprotab berpengaruh meningkatkan kekerasan tablet, namun penambahan amprotab menurunkan kekerasan tablet.

Kerapuhan tablet menunjukkan ketahanan tablet terhadap abrasi pada permukaan tablet. Batas kerapuhan tablet yang masih bisa diterima adalah kurang dari $1,0 \%$. Kerapuhan di atas 1,0\% menunjukkan tablet yang rapuh dan dianggap kurang baik (Syukri, 2018).

Data yang diperoleh dari hasil analisis menunjukkan bahwa tablet pada ketujuh formula memenuhi persyaratan kerapuhan tablet yaitu kehilangan bobot tidak lebih dari $1 \%$. Persamaan untuk kerapuhan dapat diperoleh menurut pendekatan SLD yaitu :

Persamaan untuk kerapuhan dapat diperoleh menurut pendekatan SLD yaitu :

$$
\begin{aligned}
& \mathrm{Y}=0,11(\mathrm{~A})+0,002(\mathrm{~B})+0,467(\mathrm{C})+0,08(\mathrm{~A}) \\
& (\mathrm{B})-0,23(\mathrm{~A})(\mathrm{C})-0,802(\mathrm{~B})(\mathrm{C})- \\
& 0,790(\mathrm{~A})(\mathrm{B})(\mathrm{C}) \ldots \ldots \ldots \ldots \ldots \ldots \ldots \ldots \ldots . .(3)
\end{aligned}
$$

Diagram contour plot kerapuhan tablet piroksikam dapat dilihat pada Gambar 3 .

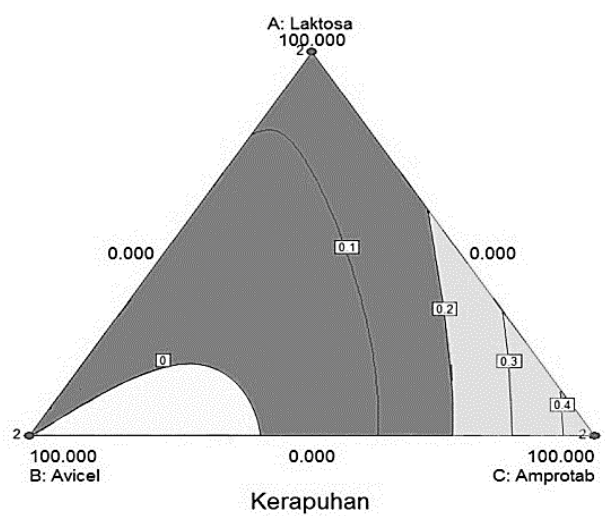

Gambar 3. Contour plot kerapuhan tablet piroksikam dengan kombinasi laktosa, avicel PH-

101, dan amprotab berdasarkan metode $S L D$

Menurut persyaratan tablet untuk kerapuhan adalah kurang dari 1,0\% (Syukri, 2018). Berdasarkan Gambar 3, diagram contour plot kerapuhan tablet menunjukkan area berwarna kuning merupakan daerah yang memenuhi persyaratan uji kerapuhan dan dapat digunakan dalam optimasi formula tablet piroksikam. Area optimum dipilih pada nilai kerapuhan 0-0,2\% ditunjukkan oleh area berwarna kuning tua, karena semakin kecil persentase kerapuhan, maka semakin kecil massa tablet yang hilang sehingga mempengaruhi keseragaman kandungan zat aktif pada tiap tablet (Syamsia et al., 2017).

Interaksi kedua komponen avicel PH-101 dan amprotab merupakan faktor yang paling dominan dalam menurunkan kerapuhan tablet. Penambahan amprotab yang lebih besar akan meningkatkan kerapuhan tablet. Semakin besar kadar laktosa dan avicel PH-101 dalam campuran formula akan mengakibatkan 
penurunan kerapuhan pada formula tablet. Bertambahnya kadar laktosa dan avicel PH101 akan membuat ikatan antar partikel menjadi lebih kuat sehingga menghasilkan tablet yang kerapuhannya lebih kecil (Tovey, 2018).

Data yang diperoleh dari hasil analisis menunjukkan bahwa bahwa sebanyak 6 formula tablet (F I, F III, F IV, F V, F VI, F VII) memenuhi persyaratan waktu hancur tablet yaitu kurang dari 15 menit, namun pada F II (100\% avicel PH-101) memiliki waktu hancur rata-rata 19,525 menit sehingga tidak memenuhi persyaratan uji waktu hancur berdasarkan Farmakope Indonesia.

Persamaan untuk waktu hancur dapat diperoleh menurut pendekatan SLD yaitu :

$$
\begin{aligned}
& Y=3,317(\mathrm{~A})+19,525(\mathrm{~B})+2,267(\mathrm{C})- \\
& 0,468(\mathrm{~A})(\mathrm{B})+13,716(\mathrm{~A})(\mathrm{C})-38(\mathrm{~B})(\mathrm{C})- \\
& 125,65(\mathrm{~A})(\mathrm{B})(\mathrm{C}) \ldots \ldots \ldots \ldots \ldots \ldots \ldots . .(4)
\end{aligned}
$$

Menurut persyaratan tablet untuk waktu hancur adalah kurang dari 15 menit (Laili et al., 2017). Berdasarkan Gambar 4, diagram contour plot waktu hancur tablet menunjukkan area berwarna merah merupakan daerah yang memenuhi persyaratan uji waktu hancur tablet dan dapat digunakan dalam optimasi formula tablet piroksikam.

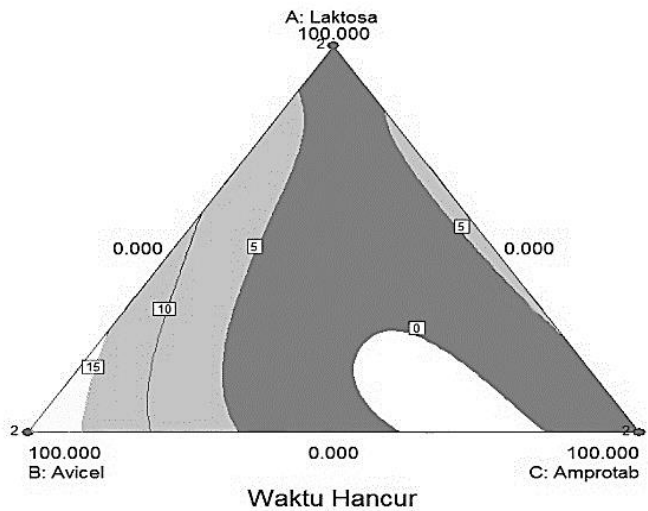

Gambar 4. Contour plot waktu hancur tablet piroksikam dengan kombinasi laktosa, avicel PH101, dan amprotab berdasarkan metode $S L D$

Area optimum dipilih pada nilai waktu hancur 0-5 menit ditunjukkan oleh area berwarna merah tua, karena waktu hancur tablet yang semakin cepat akan mempengaruhi disolusi lebih cepat, supaya obat mudah terdisolusi maka tablet harus mudah hancur dan berada dalam bentuk partikel atau granul (Graham, 2019).Interaksi ketiga komponen laktosa, avicel PH-101, dan amprotab merupakan faktor yang paling dominan dalam menurunkan waktu hancur. Penambahan amprotab lebih besar akan meningkatkan waktu hancur tablet. Amprotab akan mengembang karena suatu cairan yang masuk ke dalam tablet, aksi ini akan melawan aksi bahan pengikat dan aksi ini akan membantu pengembangan dari beberapa komponen yang akan membantu hancurnya tablet. Pati memiliki sifat hidrofilik yang mempunyai kemampuan menyerap air dan membentuk pori-pori dalam tablet. Hal ini akan meningkatkan penetrasi air ke dalam tablet, sehingga akan mempercepat waktu hancur tablet (Sheskey et al., 2017). Semakin besar kadar amprotab dalam campuran formula akan mengakibatkan peningkatan waktu hancur pada formula tablet. Kekerasan mempengaruhi waktu hancur, avicel memiliki kekerasan yang tinggi sehingga tablet yang terlalu keras menyebabkan waktu hancur yang lebih lama meskipun avicel memiliki sifat yang sukar larut dalam air, namun ketika bahan ini kontak dengan air akan mengembang membentuk gel (hidrogel) membentuk jembatan-jembatan air yang menyebabkan jaringan ikatan semakin longgar sehingga membantu tablet lebih mudah hancur meskipun memiliki kekerasan yang tinggi (Graham, 2019).

Disolusi adalah proses melarutnya suatu bahan kimia dalam suatu pelarut. Laju disolusi merupakan perubahan bentuk padat menjadi bentuk terlarut dalam mediumnya pada waktu tertentu yang dapat mempengaruhi kecepatan dan jumlah obat yang diabsorpsi (Sheskey et al., 2017). Pada disolusi, kekerasan mempengaruhi pelepasan piroksikam dari tablet. Tablet yang semakin keras menyebabkan pori-pori tablet akan semakin kecil. Hal ini menyebabkan penetrasi pelarut akan lebih sulit untuk melakukan pembasahan sehingga proses pengembangan dan pelarutan 


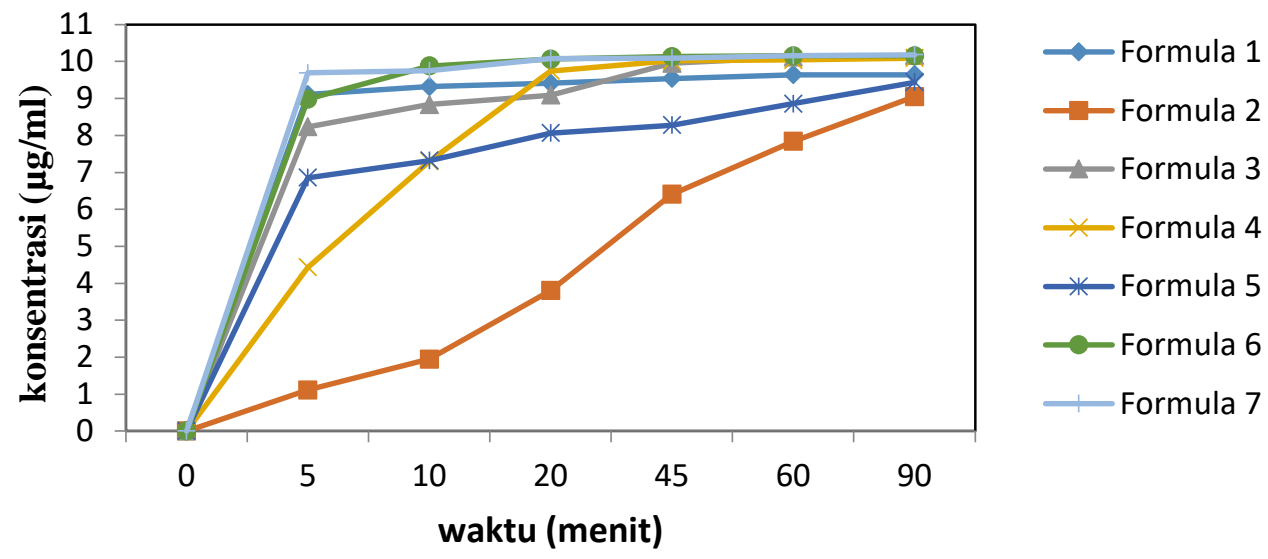

Gambar 5. Grafik profil disolusi tablet piroksikam

piroksikam dalam tablet akan lebih lambat (Suhery et al., 2016).

Persamaan regresi linear $\mathrm{y}=0,0859 \mathrm{x}-$ 0,0934 dengan koefisien korelasi $(r)=0,992$ digunakan dalam penentuan kadar piroksikam terdisolusi. Nilai koefisien korelasi tersebut lebih dari koefisien korelasi minimum untuk 6 sampel dengan derajat kebebasan 4 pada kemaknaan 0,05 yaitu 0,950 .

Analisis dari data uji disolusi ditunjukkan oleh kadar piroksikam dalam sampel pada menit ke-45 yang dinamakan metode Wagner. Metode ini menunjukkan jumlah zat aktif yang terlarut pada waktu t (Sheskey et al., 2017). Pada penelitian ini digunakan $\mathrm{C}_{45}$ artinya jumlah zat aktif telah larut dalam waktu 45 menit sebanyak 7,5 mg atau $75 \%$ mengacu pada syarat yang ditetapkan dalam USP XXIII. Formula 2 tidak memenuhi persyaratan karena nilai $\mathrm{C}_{45}$ formula 2 adalah $64,07 \%$, hal ini dipengaruhi karena kekerasan yang tinggi sehingga tablet dengan eksipien $100 \%$ avicel ini sulit mengembang dan hancur, sehingga tablet yang diperoleh sukar terlarut.

Grafik profil disolusi tablet piroksikam dapat dilihat pada gambar 5.

Persamaan untuk disolusi dapat diperoleh menurut pendekatan SLD yaitu :

$$
\begin{aligned}
& Y=9,539(\mathrm{~A})+6,407(\mathrm{~B})+9,951(\mathrm{C})+8,192 \\
& (\mathrm{~A})(\mathrm{B})-5,880(\mathrm{~A})(\mathrm{C})+7,816(\mathrm{~B})(\mathrm{C})+ \\
& 12,301(\mathrm{~A})(\mathrm{B})(\mathrm{C}) \ldots \ldots \ldots \ldots \ldots \ldots \ldots .(5)
\end{aligned}
$$

Berdasarkan persamaan (5) di atas, interaksi ketiga komponen laktosa, avicel PH 101, dan amprotab (koefisien $b_{123}$ ) merupakan faktor yang paling dominan pada uji disolusi tablet dengan nilai koefisien $b_{123}$ positif, hal ini menunjukan kombinasi ketiga bahan ini akan meningkatkan disolusi tablet. Selain itu, nilai koefisien $b_{12}$ dan $b_{23}$ positif, hal ini menunjukan kombinasi $b_{12}$ (laktosa-avicel PH-101) dan kombinasi $\mathrm{b}_{23}$ (laktosaamprotab) mempunyai pengaruh yang positif, artinya kombinasi kedua bahan akan meningkatkan disolusi tablet. Sedangkan, nilai koefisien $b_{13}$ negatif, hal ini menunjukan kombinasi $b_{13}$ (laktosa-amprotab) mempunyai pengaruh yang negatif, artinya kombinasi kedua bahan akan menurunkan disolusi tablet.

Diagram contour plot disolusi tablet piroksikam dapat dilihat pada Gambar 6.

Menurut persyaratan tablet untuk nilai $\mathrm{C}_{45}$ adalah lebih dari $75 \%$ (United States Pharmacopeia, 2014). Berdasarkan Gambar 6, diagram contour plot disolusi tablet menunjukkan area berwarna ungu merupakan daerah yang memenuhi persyaratan uji disolusi tablet dan dapat digunakan dalam optimasi formula tablet piroksikam. Semua 
area optimum pada contour plot disolusi tablet dipilih, karena disolusi merupakan parameter yang paling kritis dalam formulasi tablet piroksikam.

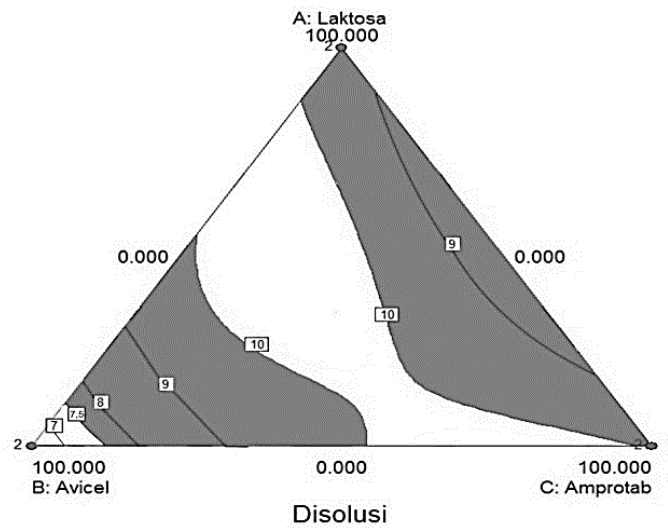

Gambar 6. Contour plot disolusi tablet piroksikam dengan kombinasi laktosa, avicel PH-101, dan amprotab berdasarkan metode $S L D$

Interaksi ketiga komponen laktosa, avicel PH-101, dan amprotab merupakan faktor yang paling dominan dalam meningkatkan kelarutan (disolusi) dari tablet piroksikam. Penambahan amprotab lebih besar akan meningkatkan disolusi tablet. Amprotab akan membentuk suatu cairan yang masuk ke dalam tablet, aksi ini akan melawan aksi bahan pengikat dan aksi ini akan membantu pengembangan dari beberapa komponen yang akan membantu hancurnya tablet (Tovey, 2018).

Semakin cepat tablet hancur maka disolusi tablet juga cenderung meningkat. Laju disolusi mempengaruhi kecepatan dan jumlah obat yang siap diabsorbsi, semakin besar jumlah zat yang terdisolusi maka semakin besar kadar obat yang terabsorbsi dalam tubuh (Tovey, 2018).

Pengujian keseragaman kadar merupakan versi kuantitatif dari pengujian identifikasi tablet. Satu tablet dari masing-masing formula digerus, dan zat aktif dalam tablet dilarutkan menggunakan pelarut HCl-metanol (1:1200). Meskipun spesifikasi untuk hasil penentuan berbeda dari satu produk terhadap produk lainnya, umumnya rentang kadar bahan aktif yang ditentukan berada diantara 97-103\% (USP, 2018).
Penentuan panjang gelombang maksimal dilakukan dengan panjang gelombang 190$380 \mathrm{~nm}$ dari hasil pengukuran absorbansi larutan baku piroksikam $5 \mu \mathrm{g} / \mathrm{mL}$ dengan pelarut metanol-HCl diperoleh panjang gelombang maksimum $332 \mathrm{~nm}$ dengan absorbansi 0,413.

Kurva baku diperoleh dengan membuat persamaan regresi absorbansi sebagai fungsi konsentrasi yaitu $\mathrm{y}=0,0894 \mathrm{x}-2,857.10^{-3}$ dengan koefisien korelasi $(r)=0,991$. Nilai koefisien korelasi tersebut lebih dari koefisien korelasi minimum untuk 6 sampel dengan derajat kebebasan 4 pada kemaknaan 0,05 yaitu 0,950 .

Persamaan untuk keseragaman kadar dapat diperoleh menurut pendekatan SLD yaitu :

$$
\begin{aligned}
& \mathrm{Y}=99,63(\mathrm{~A})+99,39(\mathrm{~B})+98,51(\mathrm{C})- \\
& 1,36(\mathrm{~A})(\mathrm{B})+5,72(\mathrm{~A})(\mathrm{C})+1,92(\mathrm{~B})(\mathrm{C})+ \\
& 53,460(\mathrm{~A})(\mathrm{B})(\mathrm{C}) \ldots \ldots \ldots \ldots \ldots \ldots \ldots \ldots . .
\end{aligned}
$$

Berdasarkan persamaan (6) di atas, laktosa merupakan faktor yang paling dominan untuk meningkatkan keseragaman kadar zat aktif dalam tablet. Selain itu, nilai koefisien $b_{12}$ negatif, hal ini menunjukan kombinasi $\mathrm{b}_{12}$ (laktosa-avicel PH-101) mempunyai pengaruh yang negatif, artinya kombinasi kedua bahan akan menurunkan keseragaman kadar zat aktif dalam tablet. Sedangkan, nilai koefisien $b_{13}$ dan $b_{23}$ positif, hal ini menunjukan kombinasi $b_{13}$ (laktosaamprotab) dan kombinasi b b $_{23}$ (avicel PH-101amprotab) mempunyai pengaruh yang positif, artinya kombinasi kedua bahan akan meningkatkan keseragaman kadar zat aktif dalam tablet. Nilai koefisien $b_{123}$ positif, hal ini menunjukan kombinasi $b_{123}$ (laktosaavicel PH-101-amprotab) mempunyai pengaruh yang positif, artinya kombinasi ketiga bahan ini akan meningkatkan keseragaman kadar zat aktif dalam tablet.

Diagram contour plot keseragaman kadar tablet piroksikam yang optimum dapat dilihat pada Gambar 7.

Menurut persyaratan tablet untuk keseragaman kadar adalah kadar tablet tidak 


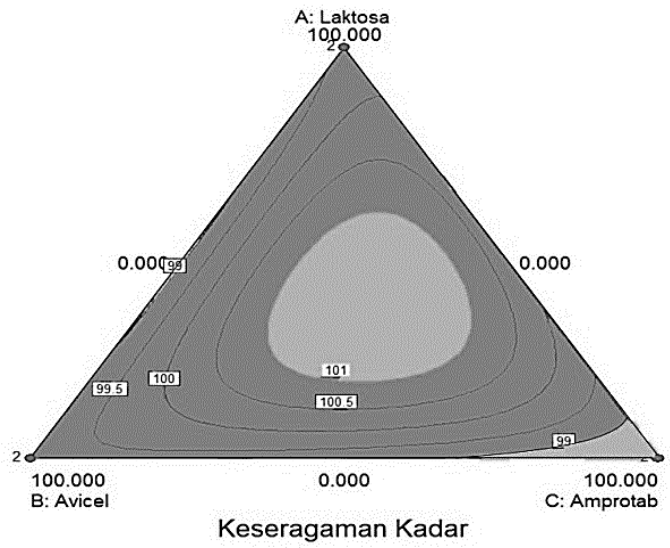

Gambar 7. Contour plot keseragaman kadar tablet piroksikam dengan kombinasi laktosa, avicel PH101, dan amprotab berdasarkan metode $S L D$

kurang dari $97 \%$ dan tidak lebih dari $103 \%$ terhadap kadar teoritik (Tovey, 2018). Diagram contour plot keseragaman kadar tablet menunjukkan area berwarna jingga merupakan daerah yang memenuhi persyaratan uji keseragaman kadar tablet dan dapat digunakan dalam optimasi formula tablet piroksikam. Area optimum dipilih pada rentang kadar 99-101\% terhadap kadar teoritik ditunjukkan oleh area berwarna jingga tua, karena pada dosis kecil seperti piroksikam, penyimpangan keseragaman kadar sedikit saja dapat berbahaya karena indeks terapinya yang sempit (Tovey, 2018).

Laktosa merupakan faktor yang paling dominan dalam meningkatkan keseragaman kadar zat aktif dalam tablet. Interaksi ketiga komponen laktosa, avicel PH-101, dan amprotab berpengaruh meningkatkan keseragaman kadar zat aktif dalam tablet, hal ini dapat diketahui dari diagram counter plot yang menjelaskan bahwa seluruh daerah merupakan area optimum untuk keseragaman kadar zat aktif piroksikam dalam tablet dari kombinasi laktosa, avicel PH-101, dan amprotab.

Menurut monografi bahwa kadar piroksikam di dalam tablet tidak kurang dari 97\% dan tidak lebih dari 103\% terhadap kadar teoritik (USP, 2018). Berdasarkan data yang didapat dari hasil pengujian, kadar piroksikam dalam masing-masing formula memenuhi rentang kadar piroksikam secara teoritik. Pada dosis kecil seperti piroksikam, penyimpangan keseragaman kadar sedikit saja dapat berbahaya karena indeks terapinya yang sempit. Pada tablet yang kadarnya kecil, adanya penyimpangan berat tidak menjamin meratanya isi, tetapi penyimpangan berat yang besar menghalangi keseragaman kandungan (Sheskey et al., 2017).

Berdasarkan keenam counter plot dari masing-masing parameter optimasi yang diuji, diperoleh grafik berupa garis yang tidak beraturan bukan merupakan garis lurus yang saling sejajar. Hal ini menunjukkan gambaran adanya interaksi antara ketiga komponen bahan (laktosa, avicel PH-101, dan amprotab) yang sangat besar sehingga menghasilkan respon yang menguntungkan (benefical effect) dan respon yang merugikan (detrimental effect).

Area optimum ditentukan pada nilai $\mathrm{CV}$ keseragaman bobot 0-0,5\%, kekerasan 4-6 kg, kerapuhan $0-0,2 \%$, waktu hancur 0-5 menit, $\mathrm{C}_{45}$ disolusi lebih dari $75 \%$, dan kadar 99$101 \%$ terhadap kadar teoritik.

Diagram superimpossed counter plot untuk tablet piroksikam dengan eksipien laktosa, avicel PH-101, dan amprotab dapat dilihat pada gambar 8 .

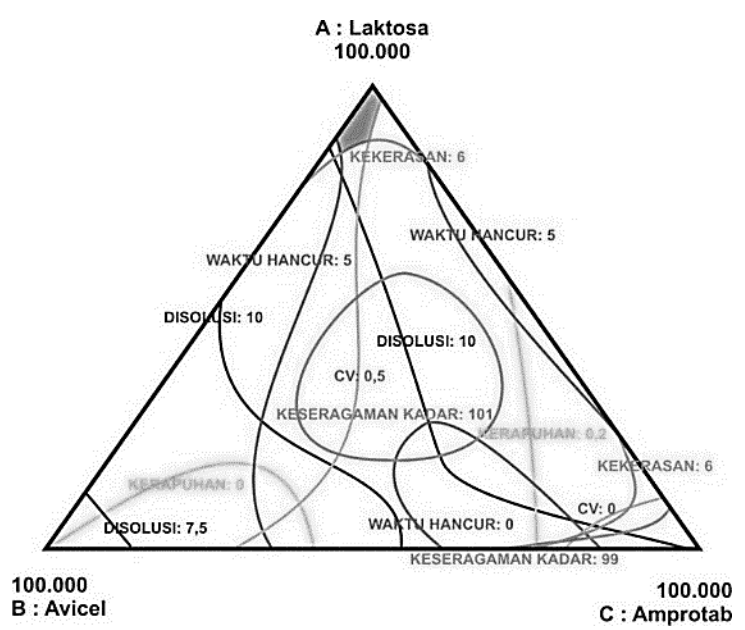

Gambar 8. Diagram superimpossed counter plot untuk tablet piroksikam dengan kombinasi laktosa, avicel PH-101, dan amprotab berdasarkan metode $S L D$ 
Komposisi formula optimum tablet piroksikam dengan kombinasi laktosa, avicel PH-101, dan amprotab dapat dilihat pada tabel 2.

Tabel 2. Komposisi formula optimum tablet piroksikam dengan kombinasi laktosa, avicel PH101, dan amprotab

\begin{tabular}{lcc}
\hline \multicolumn{1}{c}{ Bahan } & \multicolumn{2}{c}{ Komposisi formula (\%) } \\
\cline { 2 - 3 } & Minimum & Maksimum \\
\hline Laktosa & 85,154 & 100 \\
Avicel PH-101 & 0 & 12,437 \\
Amprotab & 0 & 5,425 \\
\hline
\end{tabular}

\section{KESIMPULAN}

Laktosa merupakan faktor yang paling dominan dalam meningkatkan keseragaman kadar tablet. Interaksi komponen avicel PH-
101 dan amprotab merupakan faktor yang paling dominan dalam menurunkan kerapuhan tablet. Interaksi ketiga komponen laktosa, avicel PH-101, dan amprotab merupakan faktor yang paling dominan dalam menurunkan CV keseragaman bobot, meningkatkan keseragaman bobot, meningkatkan kekerasan, menurunkan waktu hancur, dan meningkatkan disolusi tablet. Formula optimum tablet piroksikam dengan kombinasi eksipien laktosa, avicel PH-101, dan amprotab ditentukan berdasarkan diagram superimpossed counter plot yang memiliki area optimum dengan proporsi masing-masing bahan adalah sebagai berikut: laktosa (85,154-100\%), avicel PH-101 (0-12,437\%), amprotab (0-5,425\%).

\section{Daftar Pustaka}

Challener, C.A., 2015. Solid dosage and excipients: advancing development \& manufacturing, Pharmaceutical Technology.

Dipiro, J.T., Talbert, G.C., Yee, G.R., Matzke, BG., Wells, L.M., 2016. Pharmacoterapy a pathophysiologic approach eleventh edition. 1483-1535 McGrawHikk Canpantes, Inc., United States of America.

Direktorat Jenderal Pengawasan Obat dan Makanan RI, 2014, Farmakope Indonesia Jilid V, Departemen Kesehatan Republik Indonesia, Jakarta, pp.487-489, 990, 1526-1529.

Ermawati, D.E., Hidayah, N.N., Romani, S., 2018. Optimization combination of suweg starch (Amorphophallus campanulatusdecne) and gembili starch (Dioscorea esculenta (lour.) Burk.) as filler of ibuprofen tablet by simplex lattice design method. IOP conference series : materials science and engineering.

Gajera, B.Y., Rohit, P., Dugar, and Rutesh, H.D., 2016. Formulation development and optimization of ibuprofen poloxamer melt granules using hydrophilic excipients. British journal of pharmaceutical research, vol. 13(6), pp.1-19.

Graham, P. B., 2019. Good manufacturing practices for pharmaceuticals seventeitions. Crc press

Hadisoewignyo dan Fudholi, A., 2016. Sediaan solida edisi revisi. Yogyakarta: Pustaka Belajar

Islami, A., Iyan, S., Dolih, G., and Hairunnisa. 2020. Solubility modification of piroxicam : a review. Jurnal Ilmiah Farmako Bahari, Vol. 11(1), Hal 89-102.

Junaedi, F.A dan Diana, B., 2018. Teknologi informasi kesehatan I. Kementerian Kesehatan Republik Indonesia.

Katzung, B.G., 2019. Farmakologi dasar dan klinik ed.14, UI Press, Jakarta, hal : 567. 
Laili N, Annisa', M.K., Hidayaturrizqika, M., dan Suprapto, 2017. Optimasi konsentrasi amylum sagu (metroxylonrumphii) sebagai co-processed pada pembuatan tablet teofilin. Jurnal Farmasi Indonesia, 14(2), pp. 72-80.

Murtini, G., dan Yetri, E., 2018. Teknologi sediaan solid. Kementerian Kesehatan Republik Indonesia.

Rohmani, S., dan Rosyanti, H., 2019. Perbedaan metode penambahan bahan penghancur secara intragranular-ekstragranular terhadap sifat fisik serta profil disolusi tablet ibuprofen. Journal of Pharmaceutical Science and Clinical Research, 02, pp. 95-108.

Rori, W. M., Yamlean, P.V.Y., dan Sudewi, S, 2016, Formulasi dan evaluasi sediaan basah ekstrak daun gedi hijau (Abelmoschus manihot) dengan metode granulasi basah. Pharmacon Jurnal Ilmiah Farmasi UNSRAT, Vol 5(2), pp. 243-250

Sheskey., P. J., Cook W.G., Cable C.G, 2017. Handbook of pharmaceutical excipients $8^{\text {th }}$. London: Pharmaceutical Press and American Pharmacists Assosiation.

Suhery, N.W., Fernando, A., dan Giovanni, B., 2016. Perbedaan metode granulasi basah dan kempa langsung terhadap sifat fisik dan waktu hancur orally disintegrating tablets (odts) piroksikam. JurnalSains dan Farmasi Klinis, 2(2), pp. 138-144.

Suhesti, T.S., 2016, Optimasi formula tablet piroksikam menggunakan flowlac, avicel dan compritol secara cetak langsung dengan metode simplex lattice design (Thesis, Yogyakarta : Fakultas Farmasi, Universitas Gadjah Mada)

Syukri, Y., 2018. Teknologi sediaan obat dalam bentuk solid. Yogyakarta: Universitas Islam Indonesia.

Syamsia, R dan Susana, D.P., 2017. Sifat fisik tablet dihydroartemisinin-piperaquin (DHP) sediaan generik dan sediaan dengan nama dagang yang beredar di kotamadya Jayapura. Jurnal Ilmiah Farmasi, 5(3)., pp.310-314

Tovey, G. D., 2018. Pharmaceutical formulation the sciene and technology of dosage forms. Ligen. Lc, The Royal Society Chemistry.

United States Pharmacopeial Convention, 2018. The United States Pharmacopeia $28^{\text {th }}$, United States Pharmacopeia Convention Inc., Rockville, pp. 3161-3163.

United States Pharmacopeial Convention, 2018. The United States Pharmacopeia, USP 41/The national formulary, NF 36. Rockville, MD : U.S Pharmacopeial Convention, Inc., p.64596460.

Wirastuty, R. Y., 2017. Uji perbandingan sifat fisik obat cetirize generik antara produksi pabrik a, b, dan c. Jurnal Farmasi FIK UINAM, 5(1), pp. 16-22

Zen, N.I.M., Gani., S.S.A., Shamsudin, R., and Masoumi, H.R.F., 2015. The use of d-optimal mixture design in optimizing development of okara tablet formulation as a dietary supplement. The scientific world journal. 